CLINICAL STUDY

\title{
Increased basal and pulsatile secretion of FSH and LH in young men with 47,XXY or 46,XX karyotypes
}

\author{
Lise Aksglaede, Rikke Beck Jensen, Elisabeth Carlsen, Petra Kok ${ }^{1}$, Daniel M Keenan ${ }^{2}$, Johannes Veldhuis ${ }^{1}$, \\ Niels E Skakkebæk and Anders Juul \\ University Department of Growth and Reproduction GR, Rigshospitalet, University of Copenhagen, Section 5064, Blegdamsvej 9, DK-2100 \\ Copenhagen Ø, Denmark, ${ }^{1}$ Department of Internal Medicine, Mayo Clinic, Rochester, 55905 Minnesota, USA and ${ }^{2}$ Department of Statistics, University of \\ Virginia, Charlottesville, 22908 Virginia, USA \\ (Correspondence should be addressed to L Aksglaede; Email: lise.aksglaede@rh.hosp.dk)
}

\begin{abstract}
Objective: The regulation of normal sexual maturation and reproductive function is dependent on a precise hormonal regulation at hypothalamic, pituitary, and gonadal levels. The aim of this study was to investigate the neuroendocrine integrity of the pituitary-gonadal axis in patients with primary testicular failure due to supernumerary X chromosomes.

Design: Cross-sectional study.

Methods: In this study, 7 untreated patients with primary gonadal insufficiency due to SRY-positive 46,XX $(n=4)$ and 46,XXY karyotypes $(n=3)$ aged 18.8 years and 25 age-matched healthy controls participated. Reproductive hormones, testicular size, and overnight LH and FSH serum profiles and overnight urine LH and FSH excretion were determined.

Results: Basal LH and FSH secretion was elevated 6.3- and 25.4-fold respectively in the patients and the amount of LH and FSH secreted per burst were 2.0- and 6.6-fold elevated. We found significantly more $\mathrm{LH}$ but not FSH peaks per $24 \mathrm{~h}$, as estimated by the Weibull $\lambda$ analysis. There was no difference between approximate entropy ratios or Weibull $\gamma$ analyses indicating comparable orderliness and regularity of LH and FSH secretion. Overnight urinary LH and FSH excretion was significantly elevated in patients compared with controls and correlated significantly with calculated total overnight LH and FSH secretion respectively, thus validating deconvolution.

Conclusion: In this group of patients with severe hypergonadotropic hypogonadism due to a supernumerary $\mathrm{X}$ chromosome, higher basal, pulsatile, and total LH and FSH secretion were associated with significantly more LH peaks per $24 \mathrm{~h}$ in comparison with healthy controls. Thus, our data indicate that in patients with Klinefelter syndrome and XX male karyotypes the entire hypothalamic-pituitary-gonadal axis has undergone functional changes.
\end{abstract}

European Journal of Endocrinology 158 803-810

\section{Introduction}

The regulation of normal sexual maturation and reproductive function is dependent on a precise hormonal regulation at hypothalamic, pituitary, and gonadal levels. Testosterone (T) secretion by Leydig cells is driven by the pulsatile discharge of luteinizing hormone (LH) from the pituitary gland following episodic stimulation by hypothalamic gonadotropinreleasing hormone $(\mathrm{GnRH})$. LH secretion is under tight negative feedback control by $\mathrm{T}$ that is primarily exerted at the hypothalamic level. Consequently, low serum $\mathrm{T}$ is accompanied by a compensatory increase in LH concentrations (1). Equally, the neuroendocrine regulation of pituitary follicle-stimulating hormone (FSH) release is under the influence of GnRH, T, estradiol $\left(\mathrm{E}_{2}\right)$, and inhibin $\mathrm{B}$ concentrations, but other factors may influence this axis $(2,3)$.
Klinefelter syndrome (KS) is characterized by tall stature, gynecomastia, small testes, and androgen deficiency. Many of these characteristics can be attributed to the genetically determined primary gonadal defect characterized by the XXY karyotype. In adults with KS, the testes are small due to hyalinization of the seminiferous tubules, serum T levels are in the low normal range, and serum gonadotropin levels are subsequently elevated (4-8). The patients with SRYpositive 46,XX male karyotype resemble those with KS endocrinologically $(9,10)$.

The aim of this study was to evaluate the pituitarygonadal axis in young and adolescent men with gonadal insufficiency due to supernumerary X-chromosome material (47,XXY and 46,XX males) in comparison with age-matched controls using the combined strategy of deconvolution analyses and measurement of serial LH and FSH concentrations. 


\section{Materials and methods}

\section{Subjects}

A total of 32 subjects ( 25 healthy males aged 16.7-36.1 years (median 18.8 years) and 7 patients aged 16.039.1 years (median 21.0 years)) were studied.

The controls were healthy community-dwelling men recruited from two different studies $(11,12)$. Twelve subjects (aged 22.5-36.1 years (median 31.2 years)) were part of a study on diurnal rhythm in serum inhibin B levels (11). They were all within 10\% of ideal body weight, had no history of genital disorders, infertility or chronic diseases, and did not receive any medication. The remaining 13 participants (aged 16.7-18.8 years (median 17.1 years)) were recruited from a larger study on fetal growth performed on their mothers during 1985-1987 (13). Only young males with normal birth weights and normal fetal growth in the third trimester were included in the present study as described previously (12).

The patients consisted of three non-mosaic 47,XXY males and four SRY-positive 46,XX males.

The patients were referred to our clinic due to prenatal diagnosis, aberrant childhood/adolescent behavior or excessive growth, hypogonadism, or infertility. Chromosome analysis was performed on peripheral blood lymphocytes in each case. Karyotypes were established in 30 metaphases from each patient. All XX males were SRY positive (detected by PCR). The patients substituted with androgen (transdermal T, Testogel (Besins, Paris, France) $(n=4)$, peroral testosteronundecanoat, Restandol (Organon, Oss, The Netherlands) $(n=2))$ were withdrawn from treatment 14 days prior to and during the study.

None of the participants (patients and controls) had any acute or chronic illness, none received medications, or had any other verified endocrinopathy.

\section{Study design}

The participants were admitted to the department in the evening. An i.v. catheter was inserted into an antecubital vein and connected to a constant withdrawal pump (Swemed lab pump 3003; International AB, Frölunda, Sweden) by a heparinized catheter. From 2000 to $0800 \mathrm{~h}$, blood samples $(2 \mathrm{ml})$ were collected at 20 -min intervals, and consequently 36 continuous blood samples were drawn from each participant. Out of the 25 controls, 12 were examined for $24 \mathrm{~h}$ with sampling every $30 \mathrm{~min}$. Only the blood samples collected from 2000 to $0800 \mathrm{~h}$ were used for this study in these subjects.

All patients and 13 of the controls (with 20-min blood samples) collected urine overnight (12 h).

Testicular size and morphology were estimated by ultrasound (14). Height was measured by a stadiometer (Holtain Ltd, Crymych, UK) to the nearest $0.1 \mathrm{~cm}$ and weight on a digital scale (SECA delta, model 707) with a precision of $0.1 \mathrm{~kg}$. Body mass index (weight $/$ height $^{2}$ $\left.\left(\mathrm{kg} / \mathrm{m}^{2}\right), \mathrm{BMI}\right)$ was calculated.

\section{Hormone analyses}

Blood samples were clotted and centrifuged, and serum was stored at $-20{ }^{\circ} \mathrm{C}$ until hormone analyses were performed. Male reproductive hormones $\left(\mathrm{T}, \mathrm{E}_{2}\right.$, sex hormone-binding globulin (SHBG), and inhibin B) were determined in the morning blood sample at $0800 \mathrm{~h}$. In all serum samples from each individual, concentrations of LH and FSH were measured by time-resolved immunofluorometric assay (DELFIA; Wallac Inc., Turku, Finland) with detection limits of 0.05 and 0.06 IU/l respectively. Intraand interassay coefficients of variation (CV values) were both below 5\% in the LH and FSH assays.

$\mathrm{T}, \mathrm{E}_{2}$, and SHBG were measured by time-resolved fluoroimmunoassay (DELFIA, Wallac) with detection limits of $0.23 \mathrm{nmol} / \mathrm{l}, \quad 18 \mathrm{pmol} / \mathrm{l}$, and $0.23 \mathrm{nmol} / \mathrm{l}$ respectively. The intra- and inter-assay $\mathrm{CV}$ values were $<6 \%$ for both $\mathrm{T}$ and $\mathrm{E}_{2}$ and $<5.1 \%$ for SHBG. Inhibin $\mathrm{B}$ was determined using a specific two-sided enzyme immunometric assay from Oxford Bio-Innovation Ltd (Oxford, UK). The sensitivity of the inhibin B assay was $18 \mathrm{pg} / \mathrm{ml}$, and the intra- and interassay $\mathrm{CV}$ values were $<12$ and $17 \%$ respectively.

Free $\mathrm{T}$ concentration was calculated by the equation of Vermeulen et al. using a fixed albumin concentration of $43 \mathrm{~g} / \mathrm{l}(15)$.

\section{Urinary LH and FSH}

The volume of the $12 \mathrm{~h}$ urine collection was measured. To the urine sample $(2 \mathrm{ml})$ from each individual urine collection was added $80 \mu \mathrm{l}$ BSA (25\% BSA stock) and $150 \mu \mathrm{l}$ glycerol, and the urine samples were stored at $-20{ }^{\circ} \mathrm{C}$ until analysis. Urinary LH (u-LH) and FSH (u-FSH) concentrations were measured by immunofluorometric assay (DELFIA, Wallac), as described previously (16).

\section{Method for analyzing pulsatile LH and FSH secretion}

Hormonal secretion profiles were analyzed using deconvolution analysis in both the Klinefelter patients and the control subjects, in order to compare the endogenous LH and FSH secretion and its related secretion and elimination parameters in both study groups. Here we used a recently developed deconvolution method $(17,18)$ with fixed half-life for LH and fixed fast and slow half-lives for FSH. This fully automated Matlab and mathematically verified program uses the following steps/strategies in order to analyze LH and FSH secretion. First, the program detrends the data independent of the pulse frequency, after which the data are descaled. Thereafter, multiple potential pulse time sets are created by a smoothing process, based 
on a mathematical model derived from the non-linear heat diffusion equation. Subsequently, the program calculates candidate pulse time sets. A rational model structure for the secretion and elimination process includes parameters for basal secretion $\left(\beta_{0}\right)$, two halflives $\left(\alpha_{1}\right.$ and $\left.\alpha_{2}\right)$, basal and variable pulse mass $\left(\eta_{0}\right.$ and $\left.\eta_{1}\right)$, variance of pulse mass $\left(\sigma_{\mathrm{A}}\right)$, assay/measurement error $(\varepsilon)$, and three-component waveform parameters $\left(\beta_{1}\right.$, $\beta_{2}$ and $\beta_{3}$ ). During the next step of the analysis, the program calculates all parameters simultaneously. Once these parameters are defined, the last step of the analysis is to compare the goodness of fit with that using other pulse time sets based on the Akaike's information criterion (AIC) (19). The secretion and elimination parameters that the program finally calculates include basal secretion (in $\mathrm{IU} / \mathrm{l}_{\mathrm{vdl}}$ per $12 \mathrm{~h}$ ), pulsatile secretion (in $\mathrm{IU} / \mathrm{l}_{\mathrm{vdl}}$ per $12 \mathrm{~h}$ ), mass per pulse (in IU/ $\mathrm{v}_{\mathrm{vdl}}$ ), the time delay to maximal secretion from pulse onset (mode, in min), the regularity of the distribution of the pulses during the sample time period (Weibull $\gamma$ ) and the number of pulses per $24 \mathrm{~h}$ (Weibull $\lambda$ ). The $\lambda$ estimation of the Weibull distribution of interpulse intervals is more precise than the number of pulses observed per time interval sampled, since all interpulse intervals without bias introduced by edge artifacts of peaks potentially falling on the leading or trailing edge of the LH or FSH time series are used to calculate the mean $24 \mathrm{~h} \mathrm{LH}$ pulse frequency as $\lambda$. Hence, the Weibull $\lambda$ estimation is used in the present results.

\section{Statistical analysis}

Clinical and biochemical characteristics of the whole group are provided as median and interquartile ranges. Differences in anthropometric measurements and hormone concentration between patients and controls were compared using the Mann-Whitney $U$ test. Associations between urinary excretion and serum gonadotropin secretion were tested with Spearman's rank correlation coefficient. All statistical analyses were carried out using the statistical package SPSS (version 13; SPSS Inc., Chicago, IL, USA).

\section{Ethics}

The study was approved by the local ethics committee (KF 01 270862, KF 01-243/97, KF 01-229/02, and KF 01-065/03) and conducted in accordance with the Second Helsinki Declaration. Signed informed consent was obtained from all subjects and also from the parents of the participants under 18 years of age.

\section{Results}

The overnight $\mathrm{LH}$ and FSH serum profiles in patients and controls are illustrated in Fig. 1A-D. The deconvolution analysis revealed a significantly higher basal, pulsatile, and total secretion of LH and FSH in patients and the amount of FSH and LH secreted per burst was significantly higher in patients (Table 1). We found significantly more LH peaks per $24 \mathrm{~h}$ in the patients, as estimated by the Weibull $\lambda$ analysis, but no difference in the number of FSH peaks. There was no difference between the Weibull $\gamma$ analyses when comparing patients and accordingly there was no difference between approximate entropy (ApEn) FSH and $\mathrm{LH}$ ratios (Table 1 ).

Our patients had significantly lower basal serum levels of total and free $\mathrm{T}$ than controls, whereas inhibin $\mathrm{B}$ was below the detection limit in all but one patient (who had a very low concentration $(25 \mathrm{pg} / \mathrm{ml})$ ). We found no difference between $\mathrm{E}_{2}$ and SHBG between groups (Table 1).

The patients had significantly smaller testicular volumes than controls, and significantly more patients had gynecomastia and a history of cryptorchidism than controls (Table 1).

Overnight urinary concentrations of LH and FSH were significantly higher in patients (Table 1; Fig. 2). There were no overlapping values between patients and controls for FSH. The total urinary excretion of LH and FSH correlated significantly with total overnight LH $(r=0.77, P<0.0001)$ and FSH secretion $(r=0.67$, $P=0.006)$ respectively (Fig. $2 \mathrm{~A}$ and $\mathrm{B}$ ).

\section{Discussion}

In this detailed study of FSH and LH pulsatility in Klinefelter patients, we found significantly higher basal, pulsatile, and total LH and FSH secretion. The number of $\mathrm{LH}$ but not FSH pulses in Klinefelter patients was significantly higher than that in the controls. The regularity of pulsing and the mode (shape) of secretion bursts were similar in the two groups.

Basal (non-pulsatile) and total LH secretion were elevated 6.3- and 3.8-fold respectively, whereas the amount of LH secreted per pulse was elevated 2.0-fold in the patients compared with controls. An amplification of the basal and total FSH secretion of 25.4- and 13.1fold respectively was quantitated. The amount of FSH secreted per burst was 6.6-fold higher in the patients compared with controls. To our knowledge, the hypothalamic-pituitary-gonadal axis in patients with Klinefelter (47,XXY and SRY-positive 46,XX male) syndrome has not been studied in detail previously.

Our findings are in accordance with previously reported data on males with primary testicular deficiency (LH $(20,21)$ and FSH (3)). By contrast, another study found significantly more FSH peaks in males with primary testicular failure when compared with healthy controls (20). One reason for this discrepancy may be that the three previous studies on males with primary testicular failure included a total of nine patients with $47, \mathrm{XXY}$ karyotype $(n=1$ (21), $n=5$ (20), and $n=3(3)$ ), whereas the remaining patients 
A
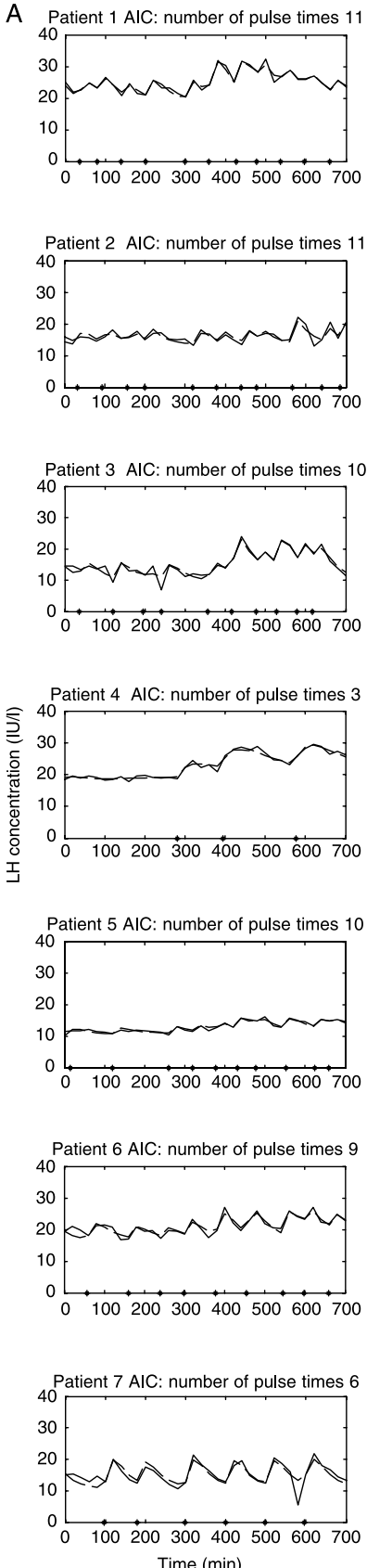

$B$

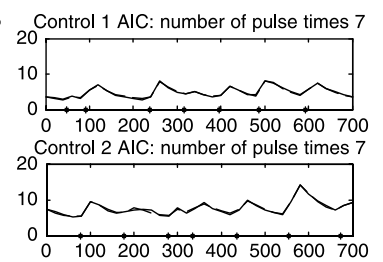
Control 3 AIC: number of pulse times 5 20
10

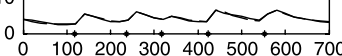
Control 4 AIC: number of pulse times 4$$
\begin{aligned}
& 20 \\
& 10 .
\end{aligned}
$$

10.

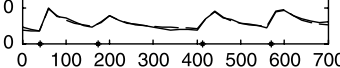
${ }_{20}$ Control $5 \mathrm{AIC}$ : number of pulse times 6 10 .

$0 \longdiv { 1 0 0 \quad 2 0 0 3 0 0 \quad 4 0 0 \quad 5 0 0 \quad 6 0 0 7 0 0 }$ Control 6 AIC: number of pulse times 6$$
{ }_{10}^{20}
$$

$0 \quad 100200300400500600700$ POntrol 7 AIC: number of pulse times 10 ¿ $0 \quad 100 \quad 200300400 \quad 500 \quad 600 \quad 700$ I Control 8 AIC: number of pulse times 6

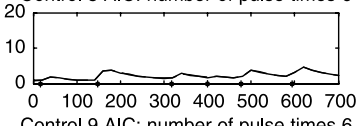
Control 9 AIC: number of pulse times 6 20
10

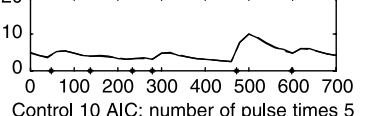
Control 10 AIC: number of pulse times 5

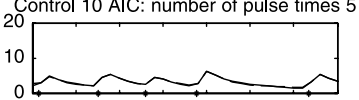

$0 \overbrace{0}^{100} 200 \quad 300400500600700$ Control 11 AIC: number of pulse times 10

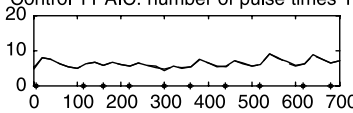

o 100200300400500600700 Control 12 AIC: number of pulse times 6

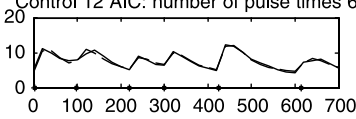
Control 13 AIC: number of pulse times 3

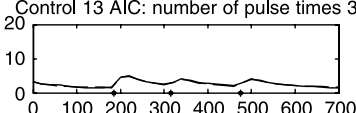

$00 \quad 100200300400500600700$ Time ( $\mathrm{min}$ )
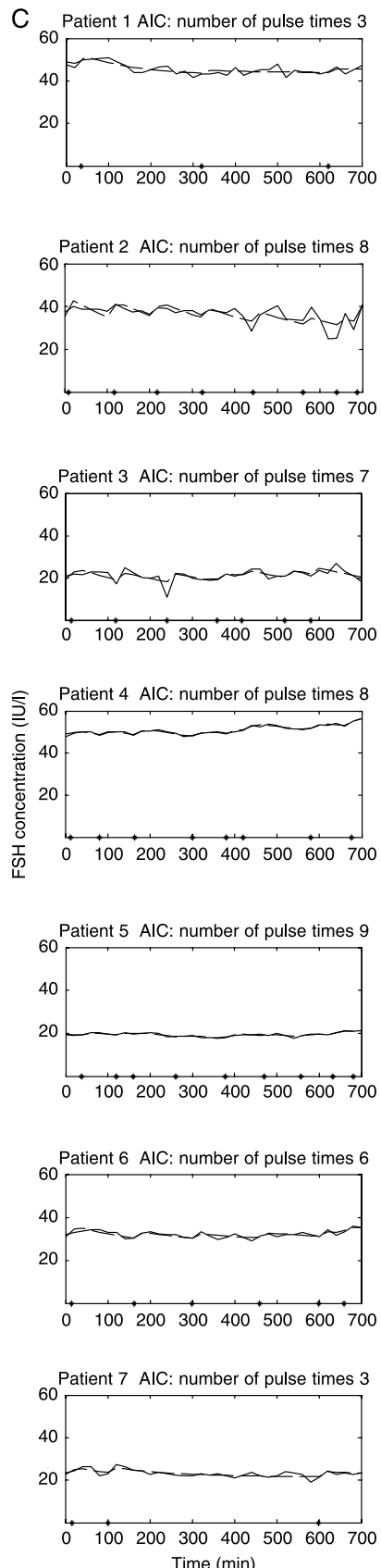

Control 1 AIC: number of pulse times 5

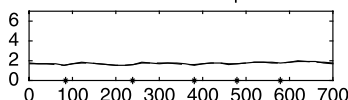
Control 2 AIC: number of pulse times 6

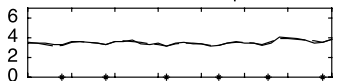

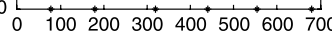
Control 3 AIC: number of pulse times 3

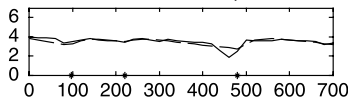
$0 \quad 100200300400500600700$
Control 4 AIC: number of pulse times 4

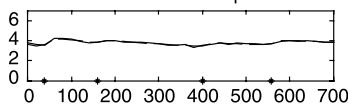
Control 5 AIC: number of pulse times 3 6
4
2
0
0
6
4
2
0

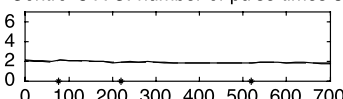

100200300400500 Control 6 AIC: number of pulse times 8 $6 \longdiv { 1 }$

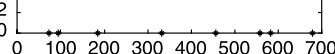
․ Control 7 AIC: number of pulse times 5

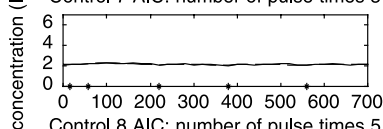

o

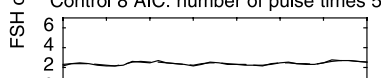

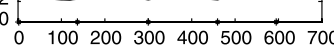
Control 9 AIC: number of pulse times 8

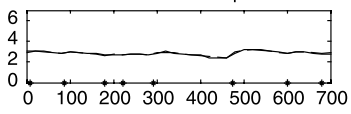
Control 10 AIC: number of pulse times 5

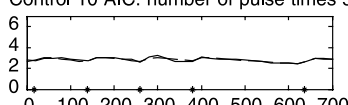

0 $1000200300 \quad 400500600700$ Control 11 AIC: number of pulse times 6

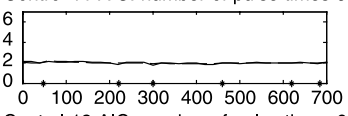
Control 12 AIC: number of pulse times 6

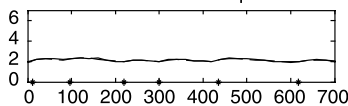
Control 13 AIC: number of pulse times

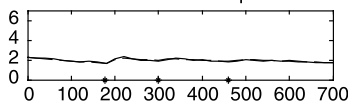
Time (min)

Figure 1 Overnight serum concentration profiles of $\mathrm{LH}$ and FSH in (A and C) patients with Klinefelter or SRY-positive XX male syndrome and (B and D) healthy controls showing the actual fit when fast half-life is fixed for LH and fast and slow half-lives for FSH are fixed. AIC denotes Akaike's information criterion as the statistically objective determinant of pulse number. Asterisks on $X$-axis defining pulse onsets (nadir preceding the following peak).

$(n=9)$ had primary testicular failure due to other reasons. Since these studies included patients with gonadal diseases other than KS, they may not be directly comparable with our study. KS is a complex entity in which numerous factors may influence the pituitary-gonadal axis.

To our knowledge, we have for the first time carried out the Weibull $\gamma$ and $\lambda$ analyses on patients with KS. $\gamma$ reflects the regularity of distribution of pulses during the sample period and $\lambda$ number of pulses per $24 \mathrm{~h}$ (calculated from the actual sample time period) respectively. We found a 1.5-fold increase in $\lambda$ for $\mathrm{LH}$ $(P=0.02)$ in the patients, with no difference in mean interpulse interval regularity $(\gamma)$ or the time required to achieve maximum secretion (mode of $13 \mathrm{~min}$ in both cases). 
Table 1 Clinical characteristics of the patients with supernumerary $X$ chromosomes and controls

\begin{tabular}{|c|c|c|c|}
\hline Median (IQR) & Patients $(n=7)$ & Controls $(n=25)$ & $P$ value \\
\hline \multicolumn{4}{|l|}{ Clinical data } \\
\hline Height $(\mathrm{cm})$ & $181.1(162.4-186.2)$ & $183.6(177.0-186.0)$ & NS \\
\hline Weight $(\mathrm{kg})$ & $71.2(67.6-77.7)$ & $75.0(68.6-82.9)$ & NS \\
\hline BMI $\left(\mathrm{kg} / \mathrm{m}^{2}\right)$ & $22.4(19.5-29.6)$ & $21.3(20.3-24.9)$ & NS \\
\hline Mean testicular volume by ultrasound $(\mathrm{ml})^{\mathrm{a}}$ & $0.93(0.79-1.51)$ & $10.75(9.1-12.2)$ & 0.001 \\
\hline Gynecomastia (\%) ${ }^{\mathrm{a}}$ & 60 & 10 & \\
\hline Cryptorchidism (\%) ${ }^{\mathrm{a}}$ & 30 & 0 & \\
\hline \multicolumn{4}{|l|}{ Basal reproductive hormones } \\
\hline Testosterone $(\mathrm{nmol} / \mathrm{l})$ & $8.0(7.2-9.9)$ & $20.3(17.1-25.5)$ & $<0.001$ \\
\hline SHBG $(\mathrm{nmol} / \mathrm{l})$ & $41(31-54)$ & $29(20-42)$ & NS \\
\hline Estradiol (pmol/l) & $71(61-73)$ & $91(66-114)$ & NS \\
\hline Inhibin B (pg/ml) & $<$ Detection limit & $199(140-237)$ & $<0.001$ \\
\hline Free testosterone $(\mathrm{pmol} / \mathrm{l})$ & $133(122-205)$ & $461(408-565)$ & $<0.001$ \\
\hline \multicolumn{4}{|l|}{ Overnight gonadotropin profiles } \\
\hline Basal overnight LH secretion (IU/I per $12 \mathrm{~h})^{a}$ & $161.4(136.2-248.2)$ & $25.7(14.8-49.7)$ & $<0.001$ \\
\hline Total secretion LH (IU// per $12 \mathrm{~h})^{\mathrm{a}}$ & $225.3(208.4-316.8)$ & $59.5(35.5-83.3)$ & $<0.001$ \\
\hline LH mass per pulse $(I U / /)^{\mathrm{a}}$ & $8.9(4.4-11.6)$ & $4.5(3.3-5.8)$ & 0.016 \\
\hline LH pulsatile secretion (IU/I per $12 \mathrm{~h})^{\mathrm{a}}$ & $68.6(47.1-89.2)$ & $28.8(17.6-36.6)$ & $<0.001$ \\
\hline LH pulse frequency per $12 \mathrm{~h}^{\mathrm{a}}$ & $10(6-11)$ & $6(5-7)$ & NS \\
\hline LH slow half-life $(\min )^{a}$ & $40.0(40.0-77.4)$ & $71.5(52.6-82.9)$ & NS \\
\hline Mode $^{\mathrm{a}}$ & $14.3(13.2-16.3)$ & $14.6(13.8-15.7)$ & NS \\
\hline Weibull $\gamma^{\mathrm{a}}$ & $4.3(3.0-5.3)$ & $4.2(3.3-9.5)$ & NS \\
\hline Weibull $\lambda^{a}$ & $17.8(13.7-19.8)$ & $11.6(10.0-13.8)$ & 0.023 \\
\hline ApEn LH ratio & $0.72(0.70-0.92)$ & $0.71(0.61-0.84)$ & NS \\
\hline Basal overnight FSH secretion (IU/l per $12 \mathrm{~h})^{\mathrm{a}}$ & $25.4(4.0-46.5)$ & $1.0(0.04-2.2)$ & 0.012 \\
\hline Total secretion FSH (IU/l per $12 \mathrm{~h})^{\mathrm{a}}$ & $50.9(31.6-64.1)$ & $3.9(2.7-5.0)$ & $<0.001$ \\
\hline FSH mass per pulse $(I U / I)^{\mathrm{a}}$ & $3.3(2.9-4.6)$ & $0.5(0.3-0.7)$ & $<0.001$ \\
\hline FSH pulsatile secretion (IU/l per $12 \mathrm{~h})^{\mathrm{a}}$ & $26.5(10.0-36.7)$ & $2.8(1.2-4.2)$ & $<0.001$ \\
\hline FSH pulse frequency per $12 \mathrm{~h}^{\mathrm{a}}$ & $7(3-8)$ & $5(3.5-6)$ & NS \\
\hline Mode $^{\mathrm{a}}$ & $8.3(7.7-11.4)$ & $10.7(8.0-14.0)$ & NS \\
\hline Weibull $\gamma^{a}$ & $4.8(2.7-5.7)$ & $3.2(2.8-7.4)$ & NS \\
\hline Weibull $\lambda^{a}$ & $13.5(4.9-13.9)$ & $9.6(7.9-11.1)$ & NS \\
\hline ApEn FSH ratio & $0.80(0.68-0.86)$ & $0.85(0.76-0.92)$ & NS \\
\hline \multicolumn{4}{|l|}{ Urinary gonadotropin secretion } \\
\hline Urinary $\mathrm{LH}\left(\mathrm{IU} / \mathrm{I}^{\mathrm{a}}\right.$ & $20.1(11.1-33.6)$ & $3.8(2.8-5.7)$ & 0.017 \\
\hline Urinary FSH $(\mathrm{IU} / \mathrm{I})^{\mathrm{a}}$ & $32.2(23.9-49.4)$ & $1.7(1.5-2.1)$ & 0.001 \\
\hline
\end{tabular}

Mann-Whitney $U$ test was used for the comparison of clinical data and basal hormones. Deconvolution analyses were compared using an unpaired $t$-test (on logarithmic data for LH). LH fast half-life and FSH fast and slow half-lives were fixed at 18, 110, and 620 min respectively.

${ }^{a}$ Comparison only between patients $(n=7)$ and controls $(n=13)$ with 20-min samples (see the Materials and methods section).

ApEn analysis was carried out in order to compare the orderliness of secretion patterns of LH and FSH. Although the patients secreted significantly more LH and FSH per $12 \mathrm{~h}$ than controls, ApEn ratios of LH and FSH did not differ between the two groups, indicating equal orderliness. This contrasts with previous findings in hypogonadal males in which a greater irregularity in FSH secretion was found (3). The reason for this could be the inclusion of males with primary gonadal deficiency due to other reasons than KS in the latter study as discussed above.

Our patients presented with the classical endocrine hallmarks of Klinefelter and 46,XX male syndromes, i.e., hypergonadotropic hypogonadism including highly elevated serum LH and FSH and low levels of serum total and free T. Additionally, inhibin B was undetectable in all but one patient (who had a very low concentration $(25 \mathrm{pg} / \mathrm{ml}))$, whereas $\mathrm{E}_{2}$ and SHBG were within the normal ranges. Urinary FSH and LH levels were clearly elevated in the patients compared with controls.
Gonadotropin synthesis and secretion is dependent upon pulsatile stimulation by the episodic secretion of hypothalamic GnRH into the pituitary portal circuation. Alterations in pulse frequency and amplitude change the relative levels of gonadotropin synthesis and release through changes in gonadotroph gene expression in the anterior pituitary $(22,23)$.

The underlying mechanism of the GnRH pulse generator is complicated and appears to be regulated at many levels, and by a variety of neural and endocrine factors. The episodic neurosecretion by the GnRH neuron is partly generated by an inhibitory autocrine feedback action of GnRH on its own secretion but is also modulated by gonadal steroid hormones and peptide hormones (23-27). In males, $\mathrm{T}$ and $\mathrm{E}_{2}$ exert independent effects on the regulation of LH secretion, whereas FSH secretion is under negative feedback control by inhibin $\mathrm{B}$, and by $\mathrm{E}_{2}$ resulting from aromatization of $\mathrm{T}$.

We found no difference in the serum levels of $E_{2}$ or SHBG between patients and controls, but free $T$ values were reduced in the patients. Therefore, the elevation in 

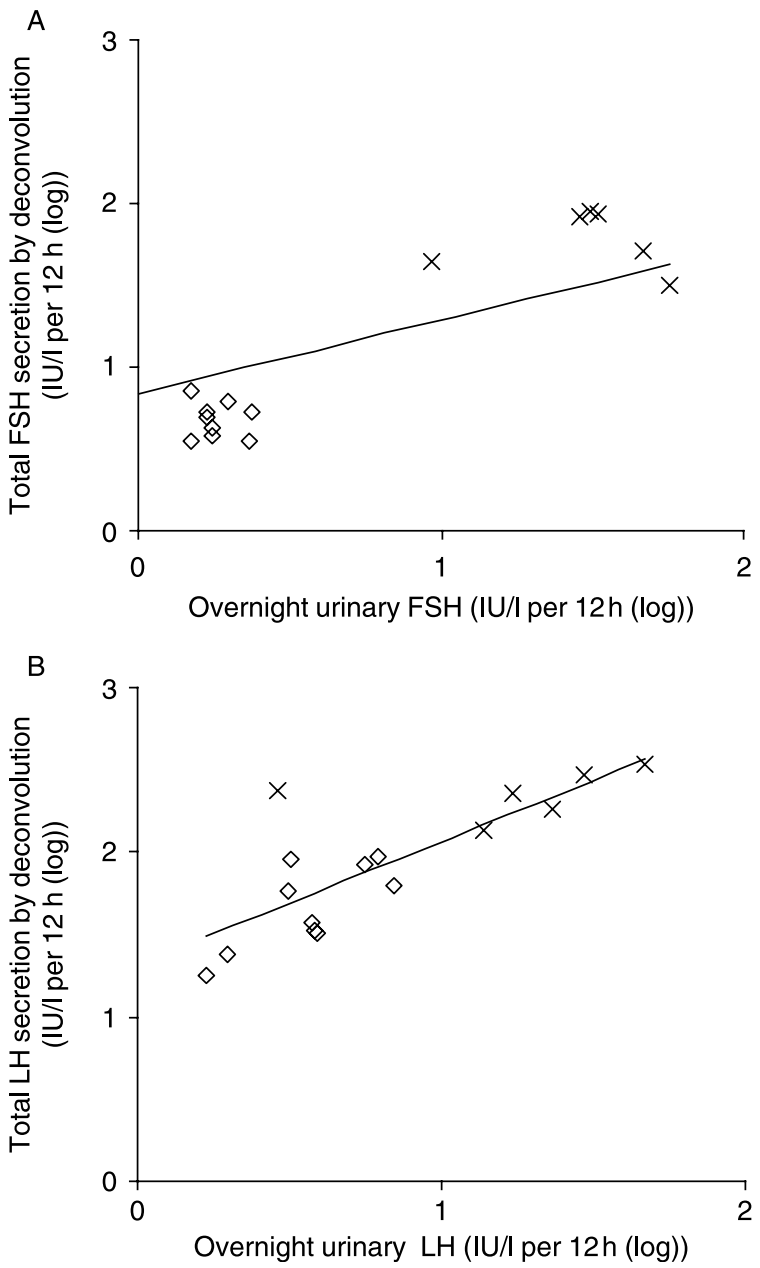

Figure 2 Twelve-hour urinary FSH (A) and $\mathrm{LH}(\mathrm{B})$ excretion in relation to total $\mathrm{LH}$ and $\mathrm{FSH}$ secretion by deconvolution in patients with Klinefelter or SRY-positive 46,XX male syndrome $(X)$ and healthy controls $(\diamond)$.

basal and pulsatile LH secretion could be attributable to the reduction in testosterone feedback. Likewise, the increase in basal FSH secretion might be due to the undetectable inhibin concentrations, possibly additionally associated with low free $\mathrm{T}$ feedback. The negative feedback from sex steroids and inhibin B exerts its effect on both hypothalamic and pituitary levels, and it may be speculated that the hypothalamic-pituitary-gonadal axis in Klinefelter and 46,XX male syndromes may be integrated at an altered set point. In our study, the serum levels of $E_{2}$ turned out to be normal in the KS subjects, and we may thereby exclude a different degree of estrogenization as a possible cause of the abnormal set point in our patients with KS since the amount of circulating estrogens is of relevance for the control of the HPG axis in healthy men $(28,29)$. However, existing data on circulating $\mathrm{E}_{2}$ levels in KS are contradicting $(4,10,30-33)$ and further studies are needed to clarify the influence of $E_{2}$ on the altered set point.
In a historic classical study by Maddock et al. supraphysiological levels of human chorionic gonadotropin (hCG) resulted in testicular atrophy (34), and more recent papers suggest that overstimulation of Leydig cells may induce apoptosis (35-37). We hypothesize that reduced testosterone secretion due to a primary defect results in hypersecretion of LH in our patients, which might result in a vicious circle producing further atrophy and increased LH secretion, thereby participating in the testicular damage in KS subjects for which the etiology remains unknown.

The increased non-pulsatile as well as total gonadotropin secretion could hypothetically have deleterious effects on the testes. In patients with KS, the testes are known to degenerate at the time of puberty, and it could be speculated that an altered hypothalamic-pituitarygonadal set point at this time may contribute to the testicular destruction resulting in a vicious circle.

Due to the differences in sampling interval, the deconvolution analyses of the patients were compared with a subgroup of controls (aged 17.1 (median) years) who were sampled in an identical way (i.e., 20-min intervals). The patients were, however, slightly but not significantly older (median 21.0 years) than controls. It is well established that the number of both the LH and FSH peaks increase with increasing age (38-40). However, when excluding the two oldest individuals (aged 34.4 and 39.1 years) in the Klinefelter group leaving the patients between 16.0 and 21.6 years of age and comparing these with the controls the number of peaks did not change for either FSH or LH.

In conclusion, we found significantly elevated basal, pulsatile, and total LH and FSH secretion when compared with healthy controls. The number of LH pulses in the Klinefelter patients was significantly higher than that in the controls. Our patients had hypergonadotropic hypogonadism due to the existence of supernumerary $\mathrm{X}$ chromosomes and the resulting primary testicular failure and none of the patients had any known pituitary defects. Thus, our data indicate that in the patients with KS and XX male karyotype, the entire hypothalamic-pituitary-gonadal axis has undergone functional changes resulting in an altered set point.

\section{Acknowledgements}

This study was in part supported by a research grant from the Kirsten \& Freddy Johansen Foundation (A Juul), the Netherlands Organization for Scientific Research (NWO, The Hague, The Netherlands) (P Kok), and the National Institutes of Health Grant (AG023133, R21023777) and National Science Foundational Grant (DMS0107680) (J Veldhuis and D Keenan). 


\section{References}

1 Veldhuis JD, Straume M, Iranmanesh A, Mulligan T, Jaffe C, Barkan A, Johnson ML \& Pincus S. Secretory process regularity monitors neuroendocrine feedback and feedforward signaling strength in humans. American Journal of Physiology. Regulatory, Integrative and Comparative Physiology 2001280 R721-R729.

2 Andersson AM, Petersen JH, Jorgensen N, Jensen TK \& Skakkebaek NE. Serum inhibin B and follicle-stimulating hormone levels as tools in the evaluation of infertile men: significance of adequate reference values from proven fertile men. Journal of Clinical Endocrinology and Metabolism 2004 89 2873-2879.

3 Veldhuis JD, Iranmanesh A \& Urban RJ. Primary gonadal failure in men selectively amplifies the mass of follicle stimulating hormone (FSH) secreted per burst and increases the disorderliness of FSH release patterns: reversibility with testosterone replacement. International Journal of Andrology $199720297-305$.

4 Lanfranco F, Kamischke A, Zitzmann M \& Nieschlag E. Klinefelter's syndrome. Lancet 2004364 273-283.

5 Paulsen CA, Gordon DL, Carpenter RW, Gandy HM \& Drucker WD. Klinefelter's syndrome and its variants: a hormonal and chromosomal study. Recent Progress in Hormone Research 1968 24 321-363.

6 Klinefelter HF, Reifenstein EC \& Albright F. Syndrome characterized by gynecomastia, aspermatogenesis without A-Leydigism, and increased excretion of follicle-stimulating hormone. Journal of Clinical Endocrinology 19422 615-627.

7 Bojesen A \& Gravholt CH. Klinefelter syndrome in clinical practice. Nature Clinical Practice. Urology 2007 4 192-204.

8 Aksglaede L, Wikstrom AM, Rajpert-De ME, Dunkel L, Skakkebaek NE \& Juul A. Natural history of seminiferous tubule degeneration in Klinefelter syndrome. Human Reproduction Update 200612 39-48.

9 de la Chapelle A. The etiology of maleness in XX men. Human Genetics 198158 105-116.

10 Vorona E, Zitzmann M, Gromoll J, Schuring AN \& Nieschlag E. Clinical, endocrinologic and epigenetic features of the 46, XX male syndrome compared to 47 , XXY Klinefelter patients. Journal of Clinical Endocrinology and Metabolism 200792 3458-3465.

11 Carlsen E, Olsson C, Petersen JH, Andersson AM \& Skakkebaek NE. Diurnal rhythm in serum levels of inhibin B in normal men: relation to testicular steroids and gonadotropins. Journal of Clinical Endocrinology and Metabolism 199984 1664-1669.

12 Jensen RB, Vielwerth S, Larsen T, Greisen G, Veldhuis J \& Juul A. Pituitary-gonadal function in adolescent males born appropriate or small for gestational age with or without intrauterine growth restriction. Journal of Clinical Endocrinology and Metabolism 2007 92 1353-1357.

13 Larsen T, Larsen JF, Petersen S \& Greisen G. Detection of small-forgestational-age fetuses by ultrasound screening in a high risk population: a randomized controlled study. British Journal of Obstetrics and Gynaecology 199299 469-474.

14 Lenz S, Giwercman A, Elsborg A, Cohr KH, Jelnes JE, Carlsen E \& Skakkebaek NE. Ultrasonic testicular texture and size in 444 men from the general population: correlation to semen quality. European Urology $199324231-238$.

15 Vermeulen A, Verdonck L \& Kaufman JM. A critical evaluation of simple methods for the estimation of free testosterone in serum. Journal of Clinical Endocrinology and Metabolism $1999 \mathbf{8 4}$ 3666-3672.

16 Demir A, Alfthan H, Stenman UH \& Voutilainen R. A clinically useful method for detecting gonadotropins in children: assessment of luteinizing hormone and follicle-stimulating hormone from urine as an alternative to serum by ultrasensitive time-resolved immunofluorometric assays. Pediatric Research 199436 221-226.

17 Keenan DM, Takahashi PY, Liu PY, Roebuck PD, Nehra AX, Iranmanesh A \& Veldhuis JD. An ensemble model of the male gonadal axis: illustrative application in aging men. Endocrinology $20061472817-2828$.
18 Keenan DM, Chattopadhyay S \& Veldhuis JD. Composite model of time-varying appearance and disappearance of neurohormone pulse signals in blood. Journal of Theoretical Biology $2005236242-255$.

19 Akaike H. A new look at the statistical model identification. IEEE Trans. Automat. Contr. AC-19:716-23, 1974. Institute of Statistical Mathematics, Minato-ku, Tokyo, Japan, 2007.

20 Matsumoto AM \& Bremner WJ. Modulation of pulsatile gonadotropin secretion by testosterone in man. Journal of Clinical Endocrinology and Metabolism 198458 609-614.

21 Winters SJ \& Troen P. A reexamination of pulsatile luteinizing hormone secretion in primary testicular failure. Journal of Clinical Endocrinology and Metabolism 198357 432-435.

22 Lawson MA, Tsutsumi R, Zhang H, Talukdar I, Butler BK, Santos SJ, Mellon PL \& Webster NJ. Pulse sensitivity of the luteinizing hormone beta promoter is determined by a negative feedback loop Involving early growth response-1 and Ngfi-A binding protein 1 and 2 . Molecular Endocrinology 200721 1175-1191.

23 Kaiser UB, Conn PM \& Chin WW. Studies of gonadotropinreleasing hormone $(\mathrm{GnRH})$ action using $\mathrm{GnRH}$ receptor-expressing pituitary cell lines. Endocrine Reviews 199718 46-70.

24 Krsmanovic LZ, Mores N, Navarro CE, Arora KK \& Catt KJ. An agonist-induced switch in $\mathrm{G}$ protein coupling of the gonadotropinreleasing hormone receptor regulates pulsatile neuropeptide secretion. PNAS 2003100 2969-2974.

25 Plant TM. Gonadal regulation of hypothalamic gonadotropin-releasing hormone release in primates. Endocrine Reviews 19867 75-88.

26 Pitteloud N, Dwyer AA, Decruz S, Lee H, Boepple PA, Crowley WF Jr \& Hayes FJ. Inhibition of LH secretion by testosterone in men requires aromatization for its pituitary but not its hypothalamic effects: evidence from the Tandem study of normal and gonadotropin-releasing hormone-deficient men. Journal of Clinical Endocrinology and Metabolism 200893 784-791.

27 Hayes FJ, Seminara SB, Decruz S, Boepple PA \& Crowley WF Jr. Aromatase inhibition in the human male reveals a hypothalamic site of estrogen feedback. Journal of Clinical Endocrinology and Metabolism 200085 3027-3035.

28 Raven G, de Jong FH, Kaufman JM \& de Ronde W. In men, peripheral estradiol levels directly reflect the action of estrogens at the hypothalamo-pituitary level to inhibit gonadotropin secretion. Journal of Clinical Endocrinology and Metabolism 200691 3324-3328.

29 Stepan JJ, Burckhardt P \& Hana V. The effects of three-month intravenous ibandronate on bone mineral density and bone remodeling in Klinefelter's syndrome: the influence of vitamin D deficiency and hormonal status. Bone 200333 589-596.

30 Aksglaede L, Skakkebaek NE \& Juul A. Abnormal sex chromosome constitution and longitudinal growth: serum levels of IGF-I, IGFBP-3, luteinizing hormone, and testosterone in 109 males with $47, \mathrm{XXY}, 47, \mathrm{XYY}$ or SRY-positive 46,XX karyotypes. Journal of Clinical Endocrinology and Metabolism 200893 169-176.

31 Bojesen A, Kristensen K, Birkebaek NH, Fedder J, Mosekilde L, Bennett P, Laurberg P, Frystyk J, Flyvbjerg A, Christiansen JS \& Gravholt CH. The metabolic syndrome is frequent in Klinefelter's syndrome and is associated with abdominal obesity and hypogonadism. Diabetes Care 200629 1591-1598.

32 Smith DA \& Walker MS. Changes in plasma steroids and bone density in Klinefelter's syndrome. Calcified Tissue Research 197722 (Suppl.) 225-228.

33 Aksglaede L, Skakkebaek NE \& Juul A. Abnormal sex chromosome constitution and longitudinal growth: serum levels of insulin-like growth factor (IGF)-I, IGF binding protein-3, luteinizing hormone, and testosterone in 109 males with $47, \mathrm{XXY}, 47, \mathrm{XYY}$, or sexdetermining region of the $\mathrm{Y}$ chromosome (SRY)-positive 46,XX karyotypes. Journal of Clinical Endocrinology and Metabolism 2008 93 169-176.

34 Maddock WO \& Nelson WO. The effects of chorionic gonadotropin in adult men: increased estrogen and 17-ketosteroid excretion, gynecomastia, leydig cell stimulation and semi-niferous tubule damage. Journal of Clinical Endocrinology and Metabolism 195212 985-1014. 
35 Heiskanen P, Billig H, Toppari J, Kaleva M, Arsalo A, Rapola J \& Dunkel L. Apoptotic cell death in the normal and cryptorchid human testis: the effect of human chorionic gonadotropin on testicular cell survival. Pediatric Research 199640 351-356.

36 Hjertkvist M, Lackgren G, Ploen L \& Bergh A. Does HCG treatment induce inflammation-like changes in undescended testes in boys? Journal of Pediatric Surgery 199328 254-258.

37 Dunkel L, Taskinen S, Hovatta O, Tilly JL \& Wikstrom S. Germ cell apoptosis after treatment of cryptorchidism with human chorionic gonadotropin is associated with impaired reproductive function in the adult. Journal of Clinical Investigation 1997100 2341-2346.

38 Veldhuis JD, Iranmanesh A, Samojlik E \& Urban RJ. Differential sex steroid negative feedback regulation of pulsatile follicle-stimulating hormone secretion in healthy older men: deconvolution analysis and steady-state sex-steroid hormone infusions in frequently sampled healthy older individuals. Journal of Clinical Endocrinology and Metabolism 199782 1248-1254.
39 Veldhuis JD, Urban RJ, Lizarralde G, Johnson ML \& Iranmanesh A. Attenuation of luteinizing hormone secretory burst amplitude as a proximate basis for the hypoandrogenism of healthy aging in men. Journal of Clinical Endocrinology and Metabolism 199275 707-713.

40 Mulligan T, Iranmanesh A, Gheorghiu S, Godschalk M \& Veldhuis JD. Amplified nocturnal luteinizing hormone (LH) secretory burst frequency with selective attenuation of pulsatile (but not basal) testosterone secretion in healthy aged men: possible Leydig cell desensitization to endogenous LH signaling a clinical research center study. Journal of Clinical Endocrinology and Metabolism 199580 3025-3031.

Received 24 January 2008

Accepted 27 February 2008 